\title{
Foot Drop due to Central cause - A Case Report on Bilateral Parasagittal Meningioma
}

\author{
HABIB R ${ }^{\mathrm{a}}$, MIZAN SB ${ }^{\mathrm{b}}$, RAHMAN A $^{\mathrm{c}}$, BHOWMIK NB $^{\mathrm{d}}$, HAQUE $^{\mathrm{e}}$
}

\begin{abstract}
Most clinicians consider a peripheral nerve lesion in patients with drop foot. However, causes stemming from the central nervous system represent rare, important, and underappreciated differential etiologies. Central causative lesions usually occur at locations where pyramidal tract connections are condensed and specific and the function is
\end{abstract}

\section{Introduction}

Foot drop is defined as a weak anterior tibialis muscle (on foot extension) and is usually caused by lower motor neuron (LMN) disease. Common causes are L4-L5 radiculopathy, caused by either a herniated nucleus pulposus or foraminal stenosis, and peroneal peripheral neuropathy. Other causes include any axonal or demyelinating damage along the whole peripheral nervous system: conus medullaris, cauda equina, nerve plexus, and peripheral mixed nerve.

Central nervous system pathology can also cause foot drop. Central causes tend to occur where nerve fibers are highly condensed along the UMN tracts: interhemispheric motor cortex homunculus (mass lesion, anterior cerebral artery stroke), corona radiata, internal capsule (lacune), cerebral peduncle (lacune), medulla, and spinal cord pyramidal tract (myelopathy). ${ }^{1}$

In case of a mid-paraasgittal lesion foot drop is due to local mass effect on the motor cortex serving the ankle and toe movements, which is on the medial homunculus

a. Dr. Rumana Habib, Registrar, Department of Neurology, BIRDEM General Hospital, Dhaka

b. Dr. Saif Bin Mizan, Resident Trainee Doctor, BIRDEM General Hospital, Dhaka

c. Dr. Aminur Rahman, Associate Professor, Department of Neurology, BIRDEM General Hospital,Dhaka

d. Dr. N.B. Bhowmik, Associate Professor, Department of Neurology, BIRDEM General Hospital, Dhaka

e. Dr. Amirul Haque, Professor, Department of Neurology, BIRDEM General Hospital, Dhaka

Address of Correspondence : Dr. Rumana Habib, Registrar, Department of Neurology, BIRDEM General Hospital, Dhaka, E-mail: drhrumana4@gmail.com

Received : April 25, 2012 Accepted: December 31, 2013 somatotopically organized. Here we report case presenting as central foot drop or spastic foot-drop and other myriad clinical features which after investigations was found due to bilateral parasagittal meningiomas.

Key words: Bilateral parasagittal meningioma; foot drop

(Birdem Med J 2014; 4(1): 52-55)

of the primary motor cortex at the mesial surface and top of the lateral surface of the precentral gyrus. Lesions in the parasagittal region that have been reported to cause foot drop include high-grade glioma, low-grade astrocytoma, abscess,metastasis, meningioma, and cerebral contusions. ${ }^{2-7}$ This area can also be affected by anterior cerebral artery stroke. ${ }^{8}$ We report here a case foot drop resulting from parasagittal meningioma.

\section{Case report}

A 65 year old diabetic, hypertensive lady got admitted because of sudden onset right sided weakness and trouble in speech for one day. On query, the patient's daughter stated that the patient had also been experiencing some headache and difficulty in walking for last six months, which had not been evaluated till date. Her headache was dull, more in morning which aggravated at straining. The patient had no history of fall, trauma to head, loss of consciousness, seizure, blurring of vision, personality changes or bowel and bladder incontinence.

On examination, the patients BP 140/90, other vitals were normal. She had aphasia and bilateral papilloedema, other cranial nerves were intact. Muscle power was 4/ 5 power in right upper limb and normal in left upper limb. In lower limbs muscle power was $3 / 5$, tone was increased along with exaggerated reflexes and illsustained clonus. Plantar response was extensor bilaterally. Cerebellar function could not be properly evaluated. The patient could not walk unaided but displayed foot drop. There was no atrophy, fasciculation, sensory deficits in the upper and lower limbs or any sensory level. 
Laboratory investigation revealed_-Hb\% : $11.1 \mathrm{gm} / \mathrm{dl}$, TC: 10180/cmm, Platelet count : 2,24,00/cmm, ESR: 42 $\mathrm{mm}$ in 1st hour. B. Urea : $26 \mathrm{mg} / \mathrm{dl}$ ， S. Creatinine : 0.8mg/dl, HbA1 C- $7.1 \%$. CXR :Normal MRI of Brain showed diffusely and strikingly enhanced smoothly contoured slightly lobulated masses in both right and left parasagittal regions, with one edge abutting the inner surface of the skull dura (Fig. 1,2,3). This was strongly suggestive of a parasagittal meningioma.

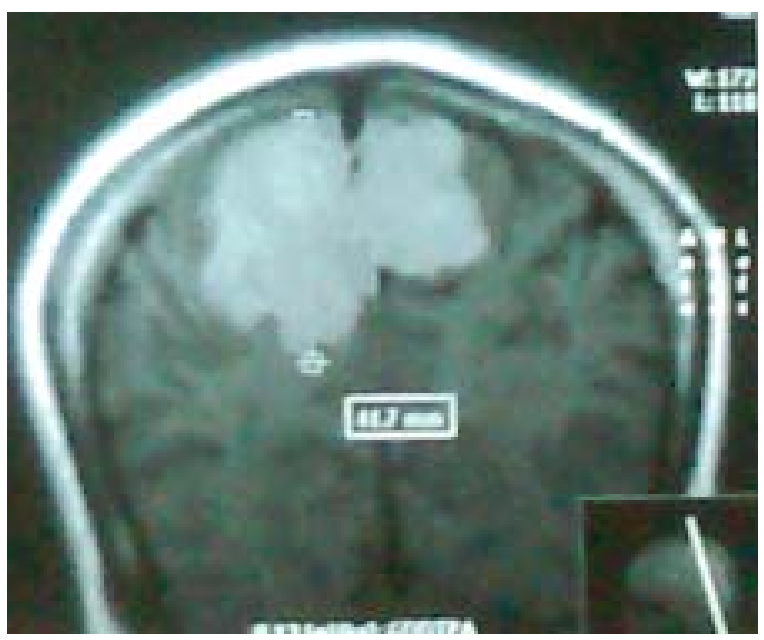

Fig.-1 : Coronal T1 weighted MRI showing well circumscribed isointense parasagittal meningioma

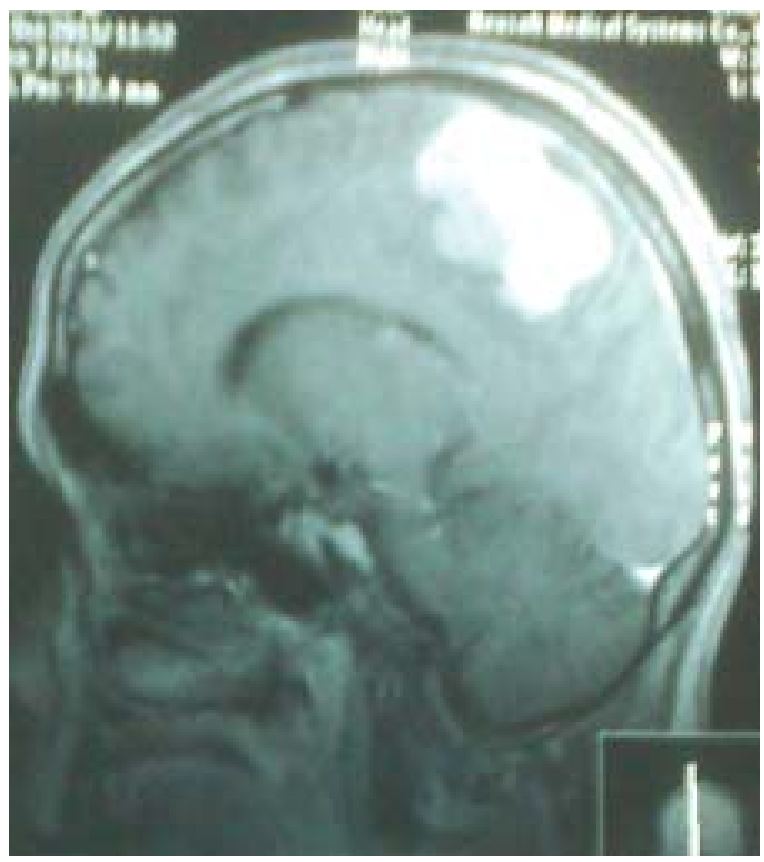

Fig.-2: Sagittal T1-weighted contrast-enhanced scan showing homogeneous contrast-enhanced parasagittal with a dural base

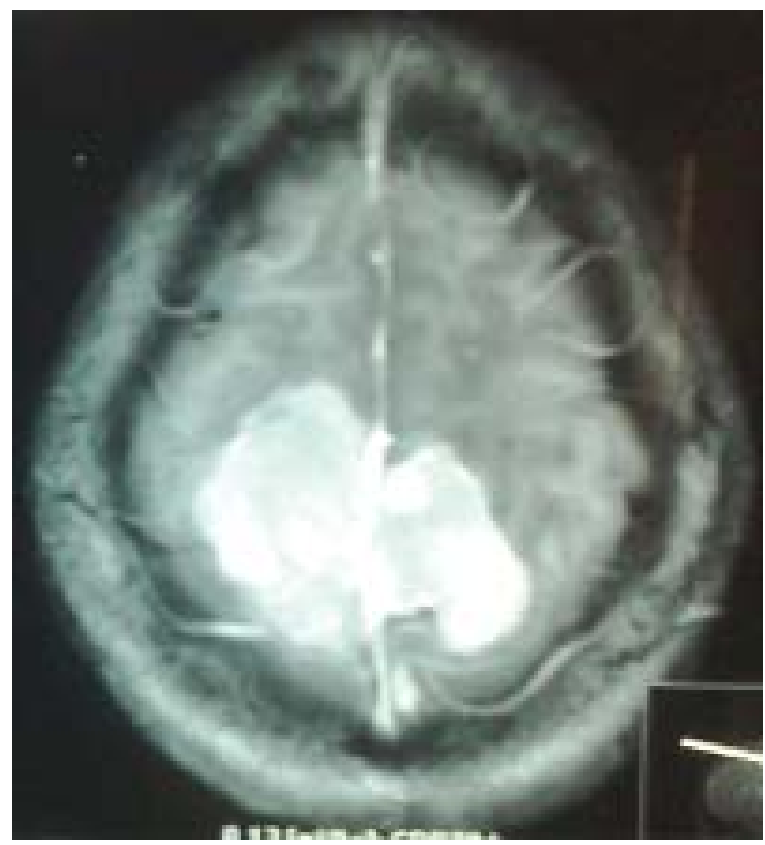

Fig 3: Axial T1-weighted contrast-enhanced scan showing homogeneously enhanced bilateral parasagittal lesion with probable sagittal venous sinus involvement

Finally we diagnosed the patient as a case of Parasagittal Meningioma with Diabetes Mellitus, Hypertension and Dyslipidaemia and treated her accordingly. The patient's symptoms improved with steroid administration temporarily.

Patient was referred to neurosurgeon after final diagnosis and as per neurosurgeon's opinion patient was discharged with advice to have immediate surgery. But our patient denied surgery.

\section{Discussion}

Meningiomas, the most common primary nonglial intracranial tumors comprises $20 \%$ to $25 \%$ of all intracranial tumors. They have a peak incidence in the middle and later decades of life. The female to male ratio is 2 to 1 in adults. ${ }^{9}$ Our patient was a 65 year old lady.

Meningiomas have a predilection for certain locations:The locations of meningiomas, in descending order of frequency, are the, parasagittal region(25\%), cerebral convexity (19\%) sphenoid wing(17\%) parasellar region(9\%), posterior fossa (8\%) olfactory groove (8\%), Middle fossa/Meckel's cave (4\%),Tentorial (3\%) and spinal canal (2\%). ${ }^{9}$ 
The term parasagittal meningioma applies to those tumors involving the sagittal sinus and the adjacent convexity dura and falx. Only the lateral wall of the sinus may be involved. or the tumor may grow to partially or completely occlude the sinus. Involvement of the overlying bone may occur with or without hyperostosis. ${ }^{10}$

In considering both the symptoms and the surgical aspects of these tumors they are divided according to the area from which they arise. i.e anterior. middle. and posterior thirds of the sagittal sinus and falx. The anterior third of the sinus extends from the crista Galli to the coronal suture. the middle third from the coronal to the lambdoid sutures. and the posterior third from the lambdoid suture to the torcular. ${ }^{10}$

Those tumors arising from the middle third of the sagittal sinus and falx are the most common and present with focal motor or sensory seizures or gradual loss of neurological function. usually beginning in the lower extremity (i.e. primarily affecting foot dorsiflexion, then knee and hip flexion). Extension of the lesion through the falx can produce bilateral leg weakness. Typically, a meningioma that forms on the left side of the falx causes right leg weakness, while a meningioma that forms on the right side of the falx causes left leg weakness. In certain cases, sensations of weakness can affect both legs. People who develop unusual sensations of leg weakness due to a parasagittal meningioma can experience difficulty standing or walking normally. ${ }^{10} \mathrm{In}$ our presentation, the patient had presumably experienced left lower limb weakness which was succeeded by right sided weakness over almost six months. Seizure was not included in her complaints. The patients dull morning headache with aggravation at straining is consistent with signs of raised ICP; a common symptom of meningiomas in any location

Similar reports of foot drop as a result of bilateral parasagittal meningioma. ${ }^{11}$, parasagittal parietal oligoastrocytoma. ${ }^{12}$ parasagittal neurocysticercusl ${ }^{13}$ were found.

Meningiomas arising from the anterior third tend to present with a gradual change in personality or progressive dementia. and/or apathy. Whereas a tumor arising from the posterior third often presents with some type of field defect. ${ }^{10}$
Meningiomas are readily visualized with contrast CT, MRI with gadolinium, and arteriography, all attributed to the fact that meningiomas are extra-axial and vascularized. Typically the tumor takes the form of smoothly contoured masses, sometimes lobulated, with one edge abutting the inner surface of the skull or the falcial or tentorial dura. MRI is superior to CT in determining dural sinus invasion with occluded venous fl ow and in defining tumor vascularity and arterial encasement. On T1-weighted images, meningiomas are isointense to hypointense to gray matter, and on T2weighted images approximately half are isointense and half are hyperintense to gray matter. There is a good correlation between tumor histology and tumor intensity on T2-weighted images, although exact histological typing by MRI is not possible. Almost all meningiomas that are hyperintense to gray matter on T2-weighted images are of the syncytial or angioblastic type, whereas fibroblastic and transitional cell types are hypointense to gray matter on T2-weighted images. Calcification is also more commonly seen in the fibroblastic and transitional types. Brain edema is seen in approximately $50 \%$ of meningiomas, with the most significant edema associated with meningiomas of the syncytial or angioblastic cell types. ${ }^{14}$ Angiography is usually needed to assess the status of the sinus and the relationship of cortical veins for proper surgical planning. In our case MRI was found to be the most helpful investigation.

Surgical excision should afford permanent cure in all symptomatic and accessible tumors. ${ }^{15}$ In our patient neurosurgical treatment was advised.

As our patient had declined surgery, we could only obtain a radiological or pathological confirmation of our diagnosis.

\section{Conclusion}

Although rare and underappreciated, central causative lesions need to be considered in the differential diagnosis of foot drop. A thorough history and physical examination may reveal signs of UMN disease, including dissociated symptoms, hyperreflexia, and Babinski response.

\section{References}

1. Westhout F D, S Paré L, Linskey ME. Central Causes of Foot Drop: Rare and Underappreciated Differential Diagnoses. J Spinal Cord Med 2007; 30(1): 62-66.

2. Baysefer A, Erdogan E, Sali A, Sirin S, Seber N. Foot drop following brain tumours: case report. Minim Invas Neorusurg 1998 ;41: 97-98. 
3. Ozdemir N, Citak G, Acar UD. Spastic foot drop caused by a brain tumor: a case report. Br J Neurosurg 2004;18: 314-35.

4. Eskandary H, Hamzei A, Yasamy MT. Foot drop following brain lesion. Surg Neurol 1995; 43:89-90.

5. Djekidel M, Harb W. A case of foot drop as an expression of brain metastases.Neurologist 2006;12:274-75.

6. Guthrie BL, Ebersold MJ, Scheithauer BW. Neoplasms of the intracranial meninges. In: Youmans JR, ed. Neurological Surgery. Philadelphia: W.B. Saunders, 1990; pp 3250-15

7. Mikuni N, Ikeda A, Yoneko H. Surgical resection of an epileptogenic cortical dysplasia in the deep foot sensorimotor area. Epilepsy Behav 2005;7:559-62.

8. Ku BD, Lee EJ, Kim H. Cerebral infarction producing sudden isolated foot drop. J Clin Neurol 2007;3:67-69.

9. Louis DN, Perry A, Heffner, Jr.RR. Cancer and the nervous system ; Pathology and molecular genetics. In: Bradley W, ed. Neurology in clinical practice. ${ }^{5 \text { th }}$ edition. Philadelphia, PA; Butterworth Heinemann 2007 : 1401-23.
10. Ojemann RG. Management of Meningiomas, PARASAGITTAL MENINGIOMA. Clinical Neurosurgery, 1992; 40: 321-83.

11. Tun K, Okutan O. Foot Drop as a Result of Bilateral Parasagittal Meningioma: A Case Report. Turkish Neurosurgery 2006; 16( 2): 94-96.

12. LeeY S, Wang P Y. Foot drop caused by a brain tumor: a case report. Acta neurologica Taiwanica 07/2009; 18(2):130-1.

13. Sahu R, Garg RK, Malhotra HS, Lalla R,.Spastic foot-drop as an isolated manifestation of neurocysticercosis. BMJ Case Rep 2012; Sep 24; Published online. (cited April 01, 2012)

14. Bhatia RG Sklar EML. Structural neurology. In: Bradley W, ed. Neurology in clinical practice. ${ }^{5 \text { th }}$ edition. Philadelphia PA; Butterworth Heinemann 2007 :521-99.

15. Samuels M A, Ropper A H eds. In: Adams and Victor's Principles of Neurology. $9^{\text {th }}$ edition. New York; McGrawHill Book company 2009:612-66. 